\title{
The Relationship between the Prevalence and Complexity of Coronary Artery Disease and Aortic Stiffness in Myocardial Infarction Patients without ST-Segment Elevation
}

\author{
Yıldırım Arafat, Mehmet Kucukosmanoglu, Gur Mustafa \\ Department of Cardiology, Adana City Training and Research Hospital, Adana, Turkey \\ ORCID: \\ Arafat Yıldırım: http://orcid.org/0000-0002-2798-7488 \\ Mehmet Kucukosmanoglu: http://orcid.org/0000-0001-9186-3642 \\ Mustafa Gur: http://orcid.org/0000-0002-3841-5282
}

\section{Abstract}

Background: The relationship between elastic properties of the aorta and presence of coronary artery disease (CAD) has been investigated in previous studies. However, the relationship of aortic stiffness (AS) with extent and complexity of CAD in patients with non-ST-segment elevation myocardial infarction (NSTMI) have not been evaluated in previous studies. Aims and Objectives: The aim of this study is to determine the relationship of AS with extent and complexity of CAD in patients with NSTMI. Materials and Methods: Study population includes 400 patients (265 men, 135 women, mean age 61,8 \pm 10.4 years) who had coronary angiography (CAG) in our clinic between February 2013 and October 2013 with the diagnosis of NSTMI. Patients were divided into two groups according to the median SYNTAX score as SYNTAX score $<16,5$ SYNTAXlow group; and SYNTAX score $\geq 16,5$ SYNTAX high group. AS parameters containing pulse wave velocity (PWV) and augmentation index (AIx) were calculated using applanation tonometry. Results: PWV and AIx parameters were found to be significantly higher $(P<0.001$ for each) in SYNTAX high group compared to SYNTAX low group. Also age, the frequency of HT (hypertension), HPL (hyperlipidemia) and DM (diabetes mellitus) were significantly higher $(P<0.05$ for all $)$ in SYNTAX high group. HT $(\beta=0.083, P=0.048)$, DM $(\beta=0.160, P<0.001)$, PWV $(\beta=0.520, P<0.001)$, and AIx $(\beta=0.230, P<0.001)$ were found to be independently associated with SYNTAX score in multivariate regression analysis. On the other hand, age $(\beta=0.255, P<0.001)$, HT $(\beta=0.212, P<0.001)$, NT-proBNP $(\beta=0.086, P=0.012)$ and SYNTAX score $(\beta=0.494, P<0.001)$ were independently associated with PWV in multivariate regression analysis. Conclusion: SYNTAX score was found to be independently associated with increased AS in NSTMI patients. Increased AS may be thought as a predictor of extent and complexity of CAD.

Keywords: AIx, aortic stiffness, coronary, NSTMI, PWV, SYNTAX

\section{INTRODUCTION}

Coronary artery disease (CAD) is one of the most important causes of morbidity and mortality worldwide. Scoring systems such as Gensini score, Negri score, and SYNTAX (Synergy between PCI and TAXUS ${ }^{\text {TM }}$ and Cardiac Surgery) score can be used for determining the prevalence and severity of CAD. SYNTAX score is a quantitative score used to predict the prognosis of CAD, as well as the prevalence and severity of CAD ${ }^{[1,2]}$

Received: 12-09-2019 Revised: 08-11-2019 Accepted: 20-11-2019

Published Online: 13-02-2020

\begin{tabular}{|l|l|}
\hline \multicolumn{3}{c|}{ Access this article online } \\
\hline Quick Response Code: & Website: \\
& \\
http://www.ijcva.com
\end{tabular}

On the other hand, studies have shown that impaired elastic parameters of the aorta can predict the presence of CAD.$^{[3-10]}$ Aortic stiffness (AS), defined as the deterioration of the viscoelastic structure of the vessel wall, is the result of structural and hemodynamic changes of the cellular

Address for correspondence: Dr. Yıldırım Arafat, Department of Cardiology, Adana Research and Training Hospital, Yüreğir, Adana, Turkey. E-mail: arafatdr@hotmail.com

This is an open access journal, and articles are distributed under the terms of the Creative Commons Attribution-NonCommercial-ShareAlike 4.0 License, which allows others to remix, tweak, and build upon the work non-commercially, as long as appropriate credit is given and the new creations are licensed under the identical terms.

For reprints contact: reprints@medknow.com

How to cite this article: Arafat Y, Kucukosmanoglu M, Mustafa G. The relationship between the prevalence and complexity of coronary artery disease and aortic stiffness in myocardial infarction patients without STsegment elevation. Int J Cardiovasc Acad 2020;6:16-21. 
and structural elements that make up the vessels. The risk factors for AS are smoking, hyperlipidemia (HPL), diabetes mellitus (DM), hypertension (HT), and advanced age, and the risk factors for AS are the same as the CAD risk factors. ${ }^{[1]}$ Pulse wave velocity (PWV) and augmentation index (AIx) are simple and accepted noninvasive methods used to determine AS. ${ }^{[12-15]}$

In the studies, the relationship between AS parameters obtained with echocardiography and applanation tonometer and the prevalence and severity of CAD was evaluated and limited information was obtained. ${ }^{[6,16-23]}$ The aim of this study is to investigate the relationship between the prevalence and complexity of CAD and PWV and AIx, which are used as AS parameters in patients with acute myocardial infarction (non-ST-segment elevation myocardial infarction [NSTEMI]) without ST-segment elevation.

\section{Methods}

Four hundred consecutive patients who applied to the Cardiology Clinic of Adana City Training and Research Hospital, between February and October 2013, with the presenting complaint of typical chest pain, and received the diagnosis of NSTEMI were included in this study. The patients were included in the study after the approval of the local ethics committee. NSTEMI diagnosis, the presence of HT and DM, and low-density lipoprotein (LDL) elevation were established according to the recommendations of current guidelines in the literature. ${ }^{[24]}$ Patients who were smoking, including those who had quit smoking in the last month, were named smokers. Patients with previously known CAD, severe valvular disease, chronic liver disease, chronic kidney disease, active malignancy, known hematological disease, presence of active infection, pregnancy, and/or suspected pregnancy were excluded from the study. In addition, patients who refused to participate in the study and did not give written consent were not included.

Coronary angiography $(\mathrm{CAG})$ was performed with Siemens (Axiom Sensis XP, Berlin, German) and Toshiba (Infinix CSI, Tokyo, Japan) devices using standard techniques. CAG evaluation and SYNTAX scoring were performed by two experienced interventional cardiologists. Patients with 50\% stenosis in the left main coronary artery and/or more than $70 \%$ stenosis in other coronary arteries were included in the study. SYNTAX score was calculated with a digital system. ${ }^{[25]}$

The patients were laid down on a hospital bed in a quiet room reserved for measurement, in the first $24 \mathrm{~h}$ after diagnostic angiography, at least 5 minutes after rest and without smoking or consuming caffeinated beverages in the last 30 minutes. AS parameters including PWV and AIx were measured using an applanation tonometer, a "MOBILE GRAPH New generation $24 \mathrm{~h}$ ABPM Classic" brand arteriography device. Height, weight, sex, and birth dates of the patients were entered in the relevant data places on the MOBILE GRAPH device. The cuff was inflated above the currently determined systolic pressure (at least $35 \mathrm{mmHg}$ higher), after the pressure measurement was done by the device. This way, brachial artery occlusion was performed and blood flow was stopped as a procedure condition during the measurement period (only 8-20 s, average $8 \mathrm{~s}$ ). The signals obtained through the tonometer were transferred to the computer through infrared, wireless network. AIx and PWV values and pressure waves were recorded together with the software developed for this purpose. In order to optimize the pressure recordings, records with operator index $90 \%$ and above were evaluated.

\section{Statistical analysis}

Kolmogorov-Smirnov test is used to determine whether the distribution of continuous variables was normal or not. Continuous variables in the group data are showed as mean standard deviation. Categorical variables are given as numbers and percentages. A comparison of continuous variables according to their distribution between groups was made by Student's $t$-test or Mann-Whitney U-test. Chi-square test and Fisher's exact test were used to compare categorical variables. Pearson correlation analysis was performed to investigate the relationship between SYNTAX score and NDH. Multivariate linear regression analysis was used to determine independent relationships between the parameters found significant in this study. $P<0.05$ is considered statistically significant. Analyses were performed using SPSS 17.0 (Chicago, IL, USA) statistical software package.

\section{RESULTS}

Totally 400 patients included to the study (mean age: $62.1 \pm 10.3$ years, $66.2 \%, n=265$ males). Patients were divided into two groups according to the median SYNTAX score. Patients with a SYNTAX score $<16.5$ were considered to be the low SYNTAX score group $(n=200)$, and patients with a SYNTAX score $\geq 16.5$ were considered to be the high SYNTAX score group $(n=200)$. The demographic characteristics of the patients are shown in Table 1. There was no difference

\begin{tabular}{lccc}
\hline $\begin{array}{l}\text { Table 1: Comparison of baseline demographic } \\
\text { characteristics of patients }(\boldsymbol{n}=\mathbf{2 0 0})\end{array}$ \\
\hline Parameter & $\begin{array}{c}\text { Low SYNTAX } \\
\text { score group }\end{array}$ & $\begin{array}{c}\text { High SYNTAX } \\
\text { score group }\end{array}$ & $\boldsymbol{P}$ \\
\hline Age (years) & $59.5 \pm 11.3$ & $64.1 \pm 9.6$ & $<0.001$ \\
Sex (male), $n(\%)$ & $132(66.0)$ & $133(66.5)$ & 0.500 \\
BMI (kg/m²) & $28.7 \pm 4.9$ & $28.1 \pm 4.6$ & 0.226 \\
HT (\%), $n(\%)$ & $72(36.0)$ & $134(67.0)$ & $<0.001$ \\
DM (\%), $n(\%)$ & $47(23.5)$ & $111(55.5)$ & $<0.001$ \\
Smoking, $n(\%)$ & $80(40.0)$ & $81(40.5)$ & 0.500 \\
HPL, $n(\%)$ & $68(34.0)$ & $85(42.5)$ & 0.049 \\
Family history, $n(\%)$ & $17(8.5)$ & $10(5.0)$ & 0.116 \\
SBP (mmHg) & $121.4 \pm 23.5$ & $122.2 \pm 20.3$ & 0.733 \\
DBP (mmHg) & $75.8 \pm 12.8$ & $76.9 \pm 13.2$ & 0.421 \\
PP (mmHg) & $44.6 \pm 13.4$ & $45.1 \pm 13.9$ & 0.703 \\
Pulse (beat/min) & $84.5 \pm 15.4$ & $87.0 \pm 15.7$ & 0.266 \\
\hline BMI Body mass
\end{tabular}

BMI: Body mass index, HT: Hypertension, DM: Diabetes mellitus, HPL: Hyperlipidemia, SBP: Systolic blood pressure, DBP: Diastolic blood pressure, PP: Pulse pressure 


\begin{tabular}{|c|c|c|c|}
\hline Parameter & Low SYNTAX score group & High SYNTAX score group & $P$ \\
\hline Glucose (mg/dl) & $137.9 \pm 69.1$ & $157.1 \pm 81.1$ & 0.011 \\
\hline Total cholesterol (mg/dl) & $192.5 \pm 46.4$ & $183.8 \pm 41.0$ & 0.046 \\
\hline Triglyceride (mg/dl) & $165.9 \pm 104.2$ & $162.5 \pm 94.0$ & 0.732 \\
\hline LDL-C (mg/dl) & $136.4 \pm 126.6$ & $118.2 \pm 36.1$ & 0.052 \\
\hline HDL-C (mg/dl) & $40.8 \pm 10.9$ & $40.0 \pm 10.9$ & 0.497 \\
\hline Creatinine $(\mathrm{mg} / \mathrm{dl})$ & $0.9 \pm 0.7$ & $0.9 \pm 0.8$ & 0.419 \\
\hline Uric acid (mg/dl) & $5.5 \pm 1.6$ & $5.5 \pm 1.5$ & 0.816 \\
\hline $\mathrm{Hs}-\mathrm{CRP}(\mathrm{mg} / \mathrm{dl})$ & $1.5 \pm 2.7$ & $2.0 \pm 3.5$ & 0.079 \\
\hline NT-proBNP (pg/ml) & $781.8 \pm 2655.9$ & $1500.1 \pm 3976.8$ & 0.034 \\
\hline CKMB (ng/ml) & $11.2 \pm 24.5$ & $18.1 \pm 33.5$ & 0.019 \\
\hline Troponin $(\mathrm{pg} / \mathrm{ml})$ & $399.4 \pm 980.9$ & $590.8 \pm 1040.9$ & 0.059 \\
\hline Hemoglobin (mg/dl) & $13.8 \pm 2.3$ & $13.9 \pm 7.0$ & 0.879 \\
\hline $\mathrm{WBC}(\mathrm{u} / \mathrm{mL})$ & $9.1 \pm 2.6$ & $8.9 \pm 2.8$ & 0.580 \\
\hline Left atrium diameter $(\mathrm{cm})$ & $3.7 \pm 0.4$ & $3.8 \pm 0.4$ & 0.508 \\
\hline Left ventricle diameter $(\mathrm{cm})$ & $4.6 \pm 0.4$ & $4.7 \pm 0.4$ & 0.435 \\
\hline Interventricular septum thickness $(\mathrm{cm})$ & $1.08 \pm 0.14$ & $1.09 \pm 0.14$ & 0.527 \\
\hline Left ventricle posterior wall thickness $(\mathrm{cm})$ & $1.05 \pm 0.14$ & $1.06 \pm 0.17$ & 0.956 \\
\hline $\mathrm{EF}(\%)$ & $55.6 \pm 7.9$ & $54.8 \pm 9.7$ & 0.331 \\
\hline $\mathrm{PWV}(\mathrm{m} / \mathrm{s})$ & $7.6 \pm 1.4$ & $9.6 \pm 2.0$ & $<0.001$ \\
\hline $\operatorname{AIx}(\%)$ & $16.9 \pm 7.7$ & $22.7 \pm 9.3$ & $<0.001$ \\
\hline
\end{tabular}

LDL-C: Low-density lipoprotein-cholesterol, HDL-C: High-density lipoprotein-cholesterol, NT-proBNP: N-terminal pro-b-type natriuretic peptide, Hs-CRP: High-sensitivity C-reactive protein, WBC: White blood cell, PWV: Pulse wave velocity, AIx: Augmentation index, EF: Ejection fraction, CKMB: Creatinine kinase myocardial band

\begin{tabular}{|c|c|c|c|c|}
\hline Parameters & $r$ & $P$ & $\boldsymbol{\beta}$ & $P$ \\
\hline \multicolumn{5}{|l|}{ SYNTAX score } \\
\hline Age & 0.315 & $<0.001$ & -0.032 & 0.419 \\
\hline HT & 0.440 & $<0.001$ & 0.083 & 0.048 \\
\hline DM & 0.371 & $<0.001$ & 0.160 & $<0.001$ \\
\hline HPL & 0.133 & 0.008 & -0.014 & 0.719 \\
\hline Total cholesterol & -0.190 & $<0.001$ & -0.043 & 0.246 \\
\hline LDL-C & -0.154 & 0.002 & -0.048 & 0.190 \\
\hline NT-proBNP & 0.138 & 0.006 & -0.053 & 0.142 \\
\hline PWV & 0.670 & $<0.001$ & 0.520 & $<0.001$ \\
\hline AIx & 0.453 & $<0.001$ & 0.230 & $<0.001$ \\
\hline \multicolumn{5}{|l|}{ PWV } \\
\hline Age & 0.488 & $<0.001$ & 0.255 & $<0.001$ \\
\hline DM & 0.286 & $<0.001$ & -0.036 & 0.326 \\
\hline HT & 0.519 & $<0.001$ & 0.212 & $<0.001$ \\
\hline NT-proBNP & 0.168 & 0.001 & 0.086 & 0.012 \\
\hline SYNTAX score & 0.670 & $<0.001$ & 0.494 & $<0.001$ \\
\hline SBP & 0.186 & $<0.001$ & 0.078 & 0.094 \\
\hline DBP & 0.114 & 0.022 & -0.002 & 0.966 \\
\hline
\end{tabular}

HT: Hypertension, DM: Diabetes mellitus, HPL: Hyperlipidemia, LDL-C: Low-density lipoprotein-cholesterol, NT-proBNP: N-terminal pro b-type natriuretic peptide, PWV: Pulse wave velocity, Aix: Augmentation index, SBP: Systolic blood pressure, DBP: Diastolic blood pressure

between the groups in terms of sex, smoking, and family history, but the mean age ( $59.5 \pm 11.3$ vs. $64.1 \pm 9.6 ; P<0.001)$, DM $(23.5 \%$ vs. $55.5 \% ; P<0.001)$, HT $(36.0 \%$ vs. $67.0 \%$; $P<0.001)$, and dyslipidemia ( $34.0 \%$ vs. $42.5 \% ; P=0.049)$ was significantly higher in the high SYNTAX score group. The basal laboratory values and echocardiography parameters of the patients are shown in Table 2. The mean fasting blood glucose $(137.9 \pm 69.1$ vs. $157.1 \pm 81.1 ; P=0.011)$, NT-proBNP (781.8 \pm 2655.9 vs. $1500.1 \pm 3976.8 ; P=0.034)$, and peak creatinine kinase myocardial band (CKMB) $(11.2 \pm 24.5$ vs. $18.1 \pm 33.5 ; P=0.019)$ was significantly higher in the high SYNTAX score group. In addition, the AS parameters, i.e. NDH and AIx, were significantly higher in the high SYNTAX score group (7.6 \pm 1.4 vs. $9.6 \pm 2.0 ; P<0.001$ and $16.9 \pm 7.7$ vs. $22.7 \pm 9.3 ; P<0.001$, respectively) [Table 2]. Table 3 summarizes the correlation between SYNTAX score and demographic and laboratory parameters. There was a significant and positive correlation between SYNTAX score and age, HT, DM, HPL, NT-proBNP, PWV, and AIx, whereas there was a significant negative correlation between total cholesterol and LDL-C [Table 3]. Multivariate logistic regression analysis showed that SYNTAX score was independently associated with HT $(P=0.048)$, DM $(P<0.001)$, PWV $(P<0.001)$, and AIx $(P<0.001)$ [Table 3]. Multivariate logistic regression analysis showed that $\mathrm{PWV}$ was independently associated with age $(P<0.001)$, HT $(P<0.001)$, NT-proBNP $(P=0.012)$, and SYNTAX score $(P<0.001)$ [Figure 1].

\section{Discussion}

Two important results were obtained in our study: (i) PWV and AIx were higher in the group with a high SYNTAX score and (ii) increased AS parameters independently predicted patients with a high SYNTAX score. These results suggest that 


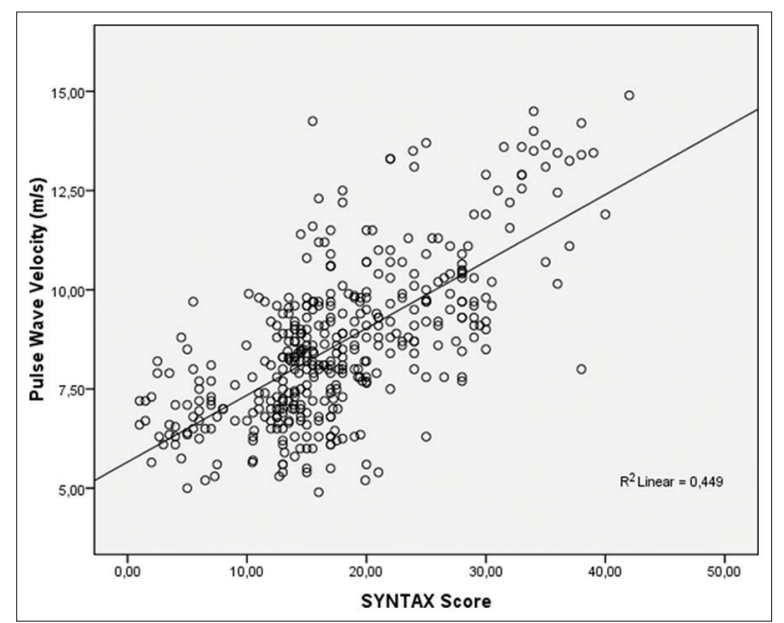

Figure 1: Relationship between pulse wave velocity and SYNTAX score $\left(R^{2}\right.$ linear $\left.=0.449\right)$

AS increases as the prevalence and complexity of CAD increase in NSTEMI patients. In addition, another important finding in our study was that the arterial stiffness parameters, i.e. PWV, age, HT frequency, NT-proBNP, and SYNTAX scores, were closely related. Several scores have been used to determine the presence and severity of CAD, and recent guidelines emphasize the use of the SYNTAX score. . $^{[1,2,23,26,27]}$ Previous studies have shown that DM and HT, which are among the traditional and modifiable risk factors of $\mathrm{CAD}$, are directly proportional to the prevalence and severity of CAD ${ }^{[28-30]}$ Similarly, in our study, it was shown that the prevalence and complexity of CAD with the SYNTAX score were independently associated with the presence of DM and HT. AS risk factors are smoking, HPL, DM, HT, renal failure, high systolic blood pressure, serum uric acid level, and advanced age, and they are similar to CAD risk factors. ${ }^{[1]}$ PWV measurement is the most simple, accepted, and most commonly used examination method in the evaluation of AS. ${ }^{[12-15]}$ In addition to PWV detected by applanation tonometer, AIx detected by the same method, PWV detected by Doppler ultrasonography, and AS detected by echocardiography can also be used as AS parameters ${ }^{[31]}$ In our study, we used PWV and AIx as AS parameters. Distortion of the elastic parameters of the aorta predicts the presence of $\mathrm{CAD}$, as it has been shown in previous studies..$^{[3-7,10]}$ In the Rotterdam study, 3000 elderly patients were included and it was shown that AS detected by PWV clearly predicted CAD and stroke development. ${ }^{[9]}$ In other studies, contradictory relationships were found between the deterioration of AS parameters obtained by echocardiographic and applanation tonometry in stable $\mathrm{CAD}$ and the presence, prevalence, and severity of CAD ${ }^{[6,16-23]}$ In the majority of studies, the prevalence and severity of CAD were associated with AS. ${ }^{[16-21]}$ However, in several studies, AS parameters were associated with the presence of CAD but not with the severity of CAD $\cdot^{[6,22,23]} \mathrm{In}$ our study, it was found that AS was independently associated with the prevalence and severity of CAD in accordance with previous studies. In the study of Alarhabi et al., PWV was found to be closely related to the severity of CAD, in addition to the presence of CAD. ${ }^{[4]}$ However, in this study, the prevalence of CAD was determined according to the number of patient vessels, which is the simplest method. Similar findings were also found by Lim et al. ${ }^{[32]}$ Although the findings of our study were similar to these two studies, there were significant differences. First of all, the severity of CAD was determined by the more acceptable and more current scoring method, SYNTAX score; second, an association with CAD severity in AIx other than PWV was established; and finally, patients with NSTEMI were also included in the study. A study similar to our study has recently been concluded. In this study conducted by Xiong et al., a positive and independent correlation was found between SYNTAX score and PWV in stable CAD patients. ${ }^{[2]}$ In the literature, there are no other data showing the relationship between AS and the prevalence and severity of CAD in NSTEMI patients. In some studies, PWV, which is an AS parameter, was found to be associated with the presence of CAD but not with the prevalence and severity of CAD. ${ }^{[6,22,23]}$ In these three studies, ${ }^{[6,22,23]}$ it was thought that PWV was not associated with CAD severity due to some limitations. In a study by Gaszner et al., PWV was not associated with SYNTAX score, but the number of patients in this study was relatively small (125 people). Another study was conducted by Seo et al., and there was no relationship between AS and CAD severity ${ }^{[23]}$ The most important limitation of this study was the use of the Gensini score, which is of less importance in CAD severity. Gensini score is not a current scoring system and does not provide important information about CAD complexity. The study conducted by Chae et al. was retrospective, and its data were thought to be insufficient in clearly determining the severity of CAD. ${ }^{[6]}$

The relationship between severity of AS and CAD have been shown in the previous studies. However this relationship has not been demonstrated in patients with NSTEMI. Our study is the first study showing the relationship between AS and the prevalence and severity of CAD in NSTEMI patients. ${ }^{[16]}$ Deterioration in both atherosclerosis and AS parameters is probably due to a general process involving all vessels. The risk factors for both conditions are similar, and these are common risk factors such as HT, DM, smoking, age, HPL, and sex..$^{[33-44]}$ Noninvasive AS parameters, which are evaluated in this field, seem to be an important parameter in predicting the presence and severity of CAD in the future.

\section{Limitations}

The most important limitation of our study is that it is a single centeer study and with a small sample size. Other important limitation is that our study did not provide prognostic information due to the lack of follow-up studies. A prognostic evaluation may be performed by studies with more patients in the future.

\section{ConcLusion}

In NSTEMI patients, SYNTAX score was independently associated with increased AS. In this patient group, increased 
AS may be a predictor of the prevalence and complexity of CAD.

\section{Financial support and sponsorship}

Nil.

\section{Conflicts of interest}

There are no conflicts of interest.

\section{RefEREnCES}

1. Valgimigli M, Serruys PW, Tsuchida K, Vaina S, Morel MA, van den Brand MJ, et al. Cyphering the complexity of coronary artery disease using the syntax score to predict clinical outcome in patients with three-vessel lumen obstruction undergoing percutaneous coronary intervention. Am J Cardiol 2007;99:1072-81.

2. Serruys PW, Morice MC, Kappetein AP, Colombo A, Holmes DR, Mack MJ, et al. Percutaneous coronary intervention versus coronary-artery bypass grafting for severe coronary artery disease. N Engl J Med 2009;360:961-72.

3. 3Achimastos A, Benetos A, Stergiou G, Argyraki K, Karmaniolas K, Thomas F, et al. Determinants of arterial stiffness in Greek and French hypertensive men. Blood Press 2002;11:218-22.

4. Alarhabi AY, Mohamed MS, Ibrahim S, Hun TM, Musa KI, Yusof Z. Pulse wave velocity as a marker of severity of coronary artery disease. J Clin Hypertens (Greenwich) 2009;11:17-21.

5. Ekici B, Erkan AF, Alhan A, Sayın I, Aylı M, Töre HF. Is mean platelet volume associated with the angiographic severity of coronary artery disease? Kardiol Pol 2013;71:832-8.

6. Chae MJ, Jung IH, Jang DH, Lee SY, Hyun JY, Jung JH, et al. The brachial ankle pulse wave velocity is associated with the presence of significant Coronary Artery disease but not the extent. Korean Circ J 2013;43:239-45.

7. Yamashina A, Tomiyama H, Arai T, Hirose K, Koji Y, Hirayama Y, et al. Brachial-ankle pulse wave velocity as a marker of atherosclerotic vascular damage and cardiovascular risk. Hypertens Res 2003;26:615-22.

8. Nam HJ, Jung IH, Kim J, Kim JH, Suh J, Kim HS, et al. Association between brachial-ankle pulse wave velocity and occult coronary artery disease detected by multi-detector computed tomography. Int J Cardiol 2012;157:227-32.

9. Mattace-Raso FU, van der Cammen TJ, Hofman A, van Popele NM, Bos ML, Schalekamp MA, et al. Arterial stiffness and risk of coronary heart disease and stroke: the Rotterdam Study. Circulation 2006;113:657-63.

10. 10Tomiyama H, Koji Y, Yambe M, Shiina K, Motobe K, Yamada J, et al. Brachial - Ankle pulse wave velocity is a simple and independent predictor of prognosis in patients with acute coronary syndrome. Circ J 2005;69:815-22.

11. 11Laurent S, Boutouyrie P. Arterial stiffness: A new surrogate end point for cardiovascular disease? J Nephrol 2007;20 Suppl 12:S45-50.

12. Laurent S, Cockcroft J, Van Bortel L, Boutouyrie P, Giannattasio C, Hayoz D, et al. Expert consensus document on arterial stiffness: Methodological issues and clinical applications. Eur Heart $\mathrm{J}$ 2006;27:2588-605.

13. Mancia G, De Backer G, Dominiczak A, Cifkova R, Fagard R, Germano G, et al. 2007 Guidelines for the management of arterial hypertension: The task force for the management of arterial hypertension of the European Society of Hypertension (ESH) and of the European Society of Cardiology (ESC). J Hypertens 2007;25:1105-87.

14. Choi CU, Park EB, Suh SY, Kim JW, Kim EJ, Rha SW, et al. Impact of aortic stiffness on cardiovascular disease in patients with chest pain: assessment with direct intra-arterial measurement. Am J Hypertens 2007;20:1163-9.

15. 15Suzuki E, Kashiwagi A, Nishio Y, Egawa K, Shimizu S, Maegawa H, et al. Brachial-ankle pulse wave velocity as an index of central arterial stiffness. J Atheroscler Thromb 201:17:658-65.

16. Yildiz A, Gur M, Yilmaz R, Demirbag R. The association of elasticity indexes of ascending aorta and the presence and the severity of coronary artery disease. Coron Artery Dis 2008;19:311-7.
17. Giannattasio C, Capra A, Facchetti R, Viscardi L, Bianchi F, Failla M, et al. Relationship between arterial distensibility and coronary atherosclerosis in angina patients. J Hypertens 2007;25:593-8.

18. Hope SA, Antonis P, Adam D, Cameron JD, Meredith IT. Arterial pulse wave velocity but not augmentation index is associated with coronary artery disease extent and severity: Implications for arterial transfer function applicability. J Hypertens 2007;25:2105-9.

19. Jankowski P, Kawecka-Jaszcz K, Czarnecka D. Ascending aortic blood pressure waveform is related to coronary atherosclerosis in hypertensive as well as in normotensive subjects. Blood Press 2007;16:246-53.

20. Kullo IJ, Bielak LF, Turner ST, Sheedy PF $2^{\text {nd }}$, Peyser PA. Aortic pulse wave velocity is associated with the presence and quantity of coronary artery calcium: A community-based study. Hypertension 2006;47:174-9.

21. Xiong Z, Zhu C, Zheng Z, Wang M, Wu Z, Chen L, et al. Relationship between arterial stiffness assessed by brachial-ankle pulse wave velocity and coronary artery disease severity assessed by the SYNTAX score. J Atheroscler Thromb 2012;19:970-6.

22. Gaszner B, Lenkey Z, Illyés M, Sárszegi Z, Horváth IG, Magyari B, et al. Comparison of aortic and carotid arterial stiffness parameters in patients with verified coronary artery disease. Clin Cardiol 2012;35:26-31.

23. Seo WW, Chang HJ, Cho I, Yoon YY, Suh JW, Kim KI, et al. The value of brachial-ankle pulse wave velocity as a predictor of coronary artery disease in high-risk patients. Korean Circ J 2010;40:224-9.

24. Roffi M, Patrono C, Collet JP, Mueller C, Valgimigli M, Andreotti F, et al. 2015 ESC Guidelines for the management of acute coronary syndromes in patients presenting without persistent ST-segment elevation: Task Force for the Management of Acute Coronary Syndromes in Patients Presenting without Persistent ST-Segment Elevation of the European Society of Cardiology (ESC). Eur Heart J 2016;37:267-315.

25. Available from: http://www.syntaxscore.com/calculator/syntaxscore/ frameset.htm. [Last accessed on 2019 Oct 10].

26. Ibanez B, James S, Agewall S, Antunes MJ, Bucciarelli-Ducci C, Bueno H, et al. 2017 ESC Guidelines for the management of acute myocardial infarction in patients presenting with ST-segment elevation: The Task Force for the management of acute myocardial infarction in patients presenting with ST-segment elevation of the European Society of Cardiology (ESC). Eur Heart J 2018;39:119-77.

27. Boutouyrie P, Tropeano AI, Asmar R, Gautier I, Benetos A, Lacolley P, et al. Aortic stiffness is an independent predictor of primary coronary events in hypertensive patients: a longitudinal study. Hypertension 2002;39:10-5.

28. Tatiana B, Peter K, Peter K, Anneliese B, Tina C. Aortic Stenting in Symptomatic Infrarenal Aortic Stenosis and Subtotal Aortic Occlusion. Vasc Endovascular Surg 2019;53:303-9.

29. Ishizaka N, Ishizaka Y, Toda E, Hashimoto H, Nagai R, Yamakado M. Higher serum uric acid is associated with increased arterial stiffness in Japanese individuals. Atherosclerosis 2007;192:131-7.

30. Lin WY, Lai MM, Li CI, Lin CC, Li TC, Chen CC, et al. In addition to insulin resistance and obesity, brachial-ankle pulse wave velocity is strongly associated with metabolic syndrome in Chinese - A population-based study (Taichung Community Health Study, TCHS). J Atheroscler Thromb 2009;16:105-12.

31. ESH/ESC Task Force for the Management of Arterial Hypertension. 2013 Practice guidelines for the management of arterial hypertension of the European Society of Hypertension (ESH) and the European Society of Cardiology (ESC): ESH/ESC Task Force for the Management of Arterial Hypertension. J Hypertens 2013;31:1925-38.

32. Lim HE, Park CG, Shin SH, Ahn JC, Seo HS, Oh DJ. Aortic pulse wave velocity as an independent marker of coronary artery disease. Blood Press 2004;13:369-75.

33. Su Z, Tan W, Shandas R, Hunter KS. Influence of distal resistance and proximal stiffness on hemodynamics and RV afterload in progression and treatments of pulmonary hypertension: a computational study with validation using animal models. Comput Math Methods Med 2013;2013:618326.

34. Nagayama D, Endo K, Ohira M, Yamaguchi T, Ban N, Kawana H, et al. Effects of body weight reduction on cardio-ankle vascular index (CAVI). Obes Res Clin Pract 2013;7:e139-45.

35. Rebić D, Rašić S, Rebić V. Impact of peritoneal dialysis treatment on 
arterial stiffness and vascular changes in diabetic type 2 and nondiabetic patients with end-stage renal disease. Int J Nephrol 2013;2013:681454.

36. Łoboz-Rudnicka M, Jaroch J, Bociaga Z, Kruszyńska E, Ciecierzyńska B, Dziuba M, et al. Relationship between vascular age and classic cardiovascular risk factors and arterial stiffness. Cardiol J 2013;20:394-401.

37. Unosson J, Blomberg A, Sandström T, Muala A, Boman C, Nyström R, et al. Exposure to wood smoke increases arterial stiffness and decreases heart rate variability in humans. Part Fibre Toxicol 2013;10:20.

38. Gentner NJ, Weber LP. Secondhand tobacco smoke, arterial stiffness, and altered circadian blood pressure patterns are associated with lung inflammation and oxidative stress in rats. Am J Physiol Heart Circ Physiol 2012;302:H818-25.

39. Coppola G, Natale F, Torino A, Capasso R, D'Aniello A, Pironti E, et al. The impact of the ketogenic diet on arterial morphology and endothelial function in children and young adults with epilepsy: A case-control study. Seizure 2014;23:260-5.

40. Chen RH, Wong SJ, Wong WH, Cheung YF. Arterial mechanics at rest and during exercise in adolescents and young adults after arterial switch operation for complete transposition of the great arteries. Am J Cardiol
2014;113:713-8.

41. Yukutake T, Yamada M, Fukutani N, Nishiguchi S, Kayama H, Tanigawa $\mathrm{T}$, et al. Arterial stiffness determined according to the cardio-ankle vascular index (CAVI) is associated with mild cognitive decline in community-dwelling elderly subjects. J Atheroscler Thromb 2014;21:49-55.

42. Waluś-Miarka M, Wojciechowska W, Miarka P, Kloch-Badełek M, Woźniakiewicz E, Czarnecka D, et al. Intima-media thickness correlates with features of metabolic syndrome in young people with a clinical diagnosis of familial hypercholesterolaemia. Kardiol Pol 2013;71:566-72.

43. Canepa M, Milaneschi Y, Ameri P, AlGhatrif M, Leoncini G, Spallarossa P, et al. Relationship between inter-arm difference in systolic blood pressure and arterial stiffness in community-dwelling older adults. J Clin Hypertens (Greenwich) 2013;15:880-7.

44. Tarumi T, Gonzales MM, Fallow B, Nualnim N, Pyron M, Tanaka H, et al. Central artery stiffness, neuropsychological function, and cerebral perfusion in sedentary and endurance-trained middle-aged adults. J Hypertens 2013;31:2400-9. 